\title{
Career Research Opportunities for the Medical Laboratory Scientist
}

\section{DAVID L MCGLASSON}

\begin{abstract}
Medical Laboratory Scientists (MLS) typically practice in hospital laboratories; however there are multiple alternatives in research. This article details the advantages of working in a variety of research laboratory settings. These include public institutions, federal laboratory workplaces, private facilities, and industry settings. A view of the different research laboratory settings such as public institutions, federal laboratory workplaces, private facilities, and industry settings will be provided. An assessment on how MLS professionals can prepare for a career in research is outlined and the report concludes with a brief summary of the various aspects of the research setting.
\end{abstract}

INDEX TERMS: research, hard money, soft money, vested, tenure

Clin Lab Sci 2011;24(3):130

David L. McGlasson, MS, MLS (ASCP) ${ }^{C M}$, 59 $9^{\text {th }}$ Clinical Research Division, Lackland AFB, TX

Address for Correspondence: David L. McGlasson, MS, MLS (ASCP) ${ }^{C M}$, Clinical Research Scientist, 2200 Bergquist Drive, Bldg. 4430, 59 th Clinical Research Division, Lackland AFB, TX 78236-9908, 210-2926555,david.mcglasson@us.af.mil

\section{INTRODUCTION}

Medical Laboratory Scientists (MLSs) and Technicians (MLTs) have a variety of employment options and career choices. Working in a research laboratory setting is one alternative to the traditional medical hospital laboratory.

Every MLS student has completed a term paper or research project. This exercise was usually looked upon as "drudgery" to endure to achieve a passing grade. Few students realize their instructors are preparing them for research as a career choice.

Research is defined as investigation or experimentation aimed at the discovery and interpretation of facts, revision of accepted laws or applications of such new or revised laws. ${ }^{1}$ Experimental science is at least 300 years old. ${ }^{1}$ Society has traditionally held a romantic role of the researcher as a single-minded scientist pursuing the truth which would unlock the "mysteries" of the universe to benefit mankind. DaVinci, Pasteur, Lister, Ehrlich, and Salk are considered demigods in their areas of research. People often forget the laboratorians who assisted those great scientists.

Until the last few decades, graduate science student assistants performed most of the laboratory work in the research setting. ${ }^{2}$ Today fewer students are pursuing graduate degrees in medical science. As large research centers have proliferated, it has become necessary to hire people whose laboratory skills guarantee continuity. These may be individuals with graduate or undergraduate degrees in a discipline such as Chemistry, Microbiology, Biology, Physics and Medical Laboratory Science. As medical schools turn out fewer research academics, MLSs with $\mathrm{PhD}$, MS, MA and BS degrees are in greater demand. ${ }^{2-5}$

In comparison to the clinical laboratory setting, the research laboratory has a different work environment to offer. The atmosphere may be more relaxed. Emergencies and interruptions are rare and equipment breakdowns are infrequent or can be managed off-line. There is less night shift, holiday or weekend work, although researchers often work odd hours to accommodate the timing of an experiment. There are problems unique to research and the MLS or MLT 


\section{CLINICAL PRACTICE}

must weigh these to determine whether they desire a research career option.

Two perspectives can be brought into focus. We can ask, "What is research and what role does the MLS play in the investigative laboratory?" and "How do MLS graduates use their education in research?" The following information provides insight into research career opportunities.

\section{Positions in Research Laboratories in State Colleges and Universities \\ Funding}

Most public university health science centers rely on a core of state taxpayer support. Each department has employees who earn "hard money." Hard money is funding by a government or organization that is repetitive, rather than a one-time grant. ${ }^{6}$ However "permanent" hard money may be redistributed if a researcher or administrator leaves or changes positions. A new leader may choose a new direction and everyone's status changes. For example, an MLS may have performed the same procedures for several years and appear to the leader to be unable to respond to new demands. Researchers or administrators may occasionally release long-term laboratory scientists in preference to their own selected staff.

Research staff members are occasionally switched to "soft money." Soft money is a term for funding that is tied to a grant that has a limited award time for a specific purpose. If the time expires and the grant is not renewed, it could put an end to the project, leaving the employee looking for a new position. When time expires or the grant is not renewed, the technologist may expect to be terminated. If the technologist has over time built a reasonable salary base, it may be too much for a new grant to support. This is a worst-case scenario as most public research institutions attempt to retain competent technologists, avoiding the necessity for recruitment and training.

\section{The MLS Advantage}

Many researchers prefer to employ MLSs for their unique technical skills. MLSs correctly execute basic laboratory procedures such as pipetting, separation, centrifugation, performing quantitative computations, preparing reagents and buffers and managing and disposal of contaminated biological or radioactive materials. The MLS by virtue of academic preparation reduces contamination despite the need to multitask and report large volumes of data. Orientation time is shortened.

Consider the following: A major state university health science center in Texas usually starts individuals classified as a MLS1 (BS, certification and 0 years experience) at a salary $\$ 4,000-6,000$ higher than a research assistant (BS, no certification and 0 years of experience) working only in research. MLS's may work as Research Assistants, but usually not vice versa. Someone who is not trained as a MLS will not receive the extra pay a MLS may receive. Salaries are usually standardized throughout the system. However salaries in these research settings may be lower than for a MLS in hospital laboratories. This information was obtained from the Human Resource Department at the University of Texas Health Science Center, San Antonio, TX. ${ }^{7}$

\section{Career Ladder}

Career ladder programs provide promotion, increased authority, and incremental pay increases as technologists gain experience. Research Assistants move up to Senior Research Assistants or Research Associates as they attain experience, education and seniority.

Public institution benefits may include in-service (local) continuing education. While personnel in research support positions do not ordinarily write grants or publish their own research, if they contribute significantly to a research project, they may achieve coauthor status upon publication.

Unless research funding is small or the economy dictates budgetary limitations, public university health science centers, public medical centers, and research foundations usually have openings for qualified personnel.

A medical laboratory researcher working at one public institution gave the following testimonial: 


\section{CLINICAL PRACTICE}

"I have a fairy-tale job. I do research on new antifungal agents and test new drugs on patients in clinical trials and I perform clinical work with patient specimens. The world of fungal testing is busier than ever before. Lifesaving medical advances, such as chemotherapy, keep cancer patients alive but suppress their immune systems. These have led to an increase in fungal infections throughout the world. We are always testing new agents that may reduce or better control these infections. Whatever the job, there will be some onthe-job training, but when you graduate from a Medical Laboratory Science program, you will have all the skills and tools you need to be effective in whatever career path you choose."

\section{Annette Fothergill, MA, MBA MLS(ASCP) \\ Fungus Testing Laboratory \\ University of Texas Health Science Center at San Antonio, TX (UTHSC/SA) \\ Annette is a 1987 graduate of the MLS program at the UTHSC/SA. ${ }^{8}$}

\section{Federal Government Research Institutions}

Most federal research agencies are adequately funded. Positions are stable, salaries are competitive, and benefits are excellent. Salary may vary by agency and its location. The National Institutes of Health (NIH) in Bethesda, Maryland is the classic example of a federally funded agency.

Many NIH laboratorians are funded by hard money. Their positions are classified by the Civil Service Commission. According to the Bureau of Labor and Statistics, Occupational Outlook handbook, 2010-11, ${ }^{4}$ salaries for federal MLS personnel averages \$5,00012,000 per year higher than other MLS venues. An MLS just out of school with a BS degree and certification but no experience would start as a GS-7/9 (GS stands for a General Schedule classification pay grade). An MLS with a BS degree, certification and two years' experience would begin at GS-9. Salaries fluctuate annually as dictated by governmental pay increases and locality pay differences. There are built in step increases in salary if good annual rating evaluations are received.
GS-11 positions and above usually require a Masters or $\mathrm{PhD}$. There is generally money available for continuing education-a rarity in this day of budget deficits in clinical laboratories. Positions are stable and provide a sense of security. Some agencies allow the laboratorian to perform independent research using in-house departmental funding. It is possible to be recognized as a contributor on publications and MLSs may conduct their own research and achieve "first author" status.

Military research facilities offer opportunities for MLSs to work as either civilian or military personnel. Civilian personnel are GS rated while military personnel hold the rank they have earned in the military system. The Clinical Research Division, Wilford Hall Medical Center at Lackland Air Force Base in San Antonio, Texas is a good example of an opportunity for a MLS working in research. This is a modern, up-to-date facility with the latest equipment. All of the positions are currently hard money slots. Positions are rated GS 9-13 with the same step increases available at NIH. The 2010 pay scale is $\$ 40,000-111,000 .^{4}$

If an MLS chooses to join the active duty military, there are a number of opportunities. A BS, certified MLS would be commissioned as a $2^{\text {nd }}$ Lieutenant, laboratory officer, or with 5 years experience, a $1^{\text {st }}$ Lieutenant. For an MLS, a Master's degree $1^{\text {st }}$ Lieutenant rank is automatic. An MLS with a $\mathrm{PhD}$ may enter as a Captain. Most laboratory officers now have earned an MLS background before entering into the military, and further education is strongly encouraged. The United States Air Force sends a large number of MLS laboratory officers each year for Master's degree, PhD. and fellowship programs. These programs are fully funded and the MLS receives salary plus education expenses while attending graduate studies. They then pay back to the military by serving 3 years in exchange for a Master's and 4 years in exchange for a $\mathrm{PhD}$. A fellowship may require a one year pay-back. The regulation for this is covered under United States Air Force Instruction, AFI 36-2107.

Many laboratory officers received their advanced degrees while in the military after they had received their basic MLS training prior to entering the service. Military leaders consider that a person with a MLS 


\section{CLINICAL PRACTICE}

background is the best individual to hire for research laboratory work.

In a personal communication Colonel Paul Barnicott, USAF (retired) says he prefers an individual with a MLS background because they already have the necessary laboratory skills to perform in a clinical or research setting without having to be trained in basic procedures.

"I have one of the greatest positions for an MLS in the world. When I first interviewed for the position of a Research Medical Technologist at the $59^{\text {th }}$ Clinical Research Division at Wilford Hall Medical Center at Lackland AFB, TX, I was told "if we don't have enough to keep you busy you can perform your own research." "I felt like I was in a dream state." I get to support some great clinical research in the area of blood coagulation for military and civilian clinicians and industry. I generate my own research while working with them. I also get to work with industry on new cutting-edge technologies in the area of hemostasis. This has been a great ride since I first attended the Gradwohl School of Medical Laboratory Technique in St. Louis, MO a long time ago, amongst a number of other places.

\section{David L. McGlasson, MS, MLS(ASCP) ${ }^{\mathrm{CM}}$ \\ $59^{\text {th }}$ Clinical Research Division \\ Wilford Hall Medical Center \\ Lackland AFB, TX}

\section{Private Research Institutions}

Private institutions fall into two categories: privately funded universities and privately endowed research institutes. Due to lack of public funding, these systems may not have the resources of public universities. Jobs may be less secure, and career advancement and benefits may be less promising. Fortunately, there are many exceptions to this negative picture.

One biomedical research foundation in the Southwest, a leading institute in primate model studies, is a good example. The organization provides both hard money and soft money funded positions and a career ladder for permanent positions. Since the foundation competes with public universities for talent, salary ranges are similar. Indeed, sometimes the foundation base salary might be higher because the benefit package may not be as competitive. However, there is a career ladder similar to a large medical school offering merit and step increases. Many researchers hire from the local pool of MLSs or research scientists. Many of the positions depend on grant funding; however, in recent years funding has been secured for more permanent positions. MLSs are paid the same as research scientists in soft money positions. Soft money positions can be terminated suddenly when grant funding is terminated, however the institution tries to place exceptional scientists in other positions. Scientists try to remain flexible and keep their skills up to date.

Continuing education funds are usually tied to the grants and are provided to project directors to disburse to staff. Most research directors find it imperative to keep their staff members' skills up-to-date in the rapidly changing laboratory.

Private universities with affiliated medical centers are good locations for an MLS to find a research laboratory position. There are many similarities to privately endowed foundations. Most research positions are soft money and there may or may not be a career ladder. Additionally, the salary may be based on the research grant. Non-research personnel who are performing clinical duties may have a career ladder and usually are hard money recipients. One researcher states that for fundamental research, he prefers classically educated scientists (i.e. graduate degree trained personnel). He wanted MLS-trained individuals when large volumes of data and multi-skilled techniques had to be employed. However, this professor was in the minority when it came to choice of personnel for laboratory support positions in research. Almost all of the other researchers interviewed preferred to hire MLS trained people due to the reason previously stated. These communications were obtained in verbal conversation with each individual. In the private university setting publication opportunities depend upon the research director. Continuing education is possible through the university, but travel money is usually a premium item reserved for the research director to dispense. 


\section{CLINICAL PRACTICE}

\section{Private Industry}

Employment in private industry, the last area of research opportunity to be discussed, generally involves working for companies that develop and produce instruments, in vitro diagnostics and therapeutics. The focus in this article is on companies that develop and produce items for use in the clinical or research laboratory directly related to human or veterinary medicine.

Most of these companies have a strict corporate mentality, unlike academic institutions. Profits, losses and the "bottom line" rule this area of research.

In private industry, the higher the individual's qualifications, the more opportunities are available. There is a career ladder and stability, provided the company has a good financial status. Overall, research workers interviewed in private industry enjoy their work. They feel they have a more prestigious position than in the clinical laboratory, where they sometimes felt belittled and unappreciated. Positions are funded by hard money, although some contract hiring is done for specific projects. Successful contract laboratorians go on to be hired permanently.

Private industry salaries are generally higher than hospital salaries. There are usually no weekends, holidays or off-shift work, but this can vary with the project. Some organizations have profit sharing plans, and good productivity may be rewarded with bonuses. A good retirement plan is usually available as well as the opportunity for being vested. Vested means the right to gain distributions from a pension fund in the event of termination of employment prior to the normal retirement age. Usually this is awarded after a certain time period.

Seniority can be a negative when lay-offs occur. Those who earn more than the company wants to spend in a certain area are vulnerable. When making cut-backs, the organization will short-sightedly see research as one of the first places to reduce spending. However, as one long time researcher in private industry stated, in a personal communication, "It just depends on how critical a position you are in at the time which may determine your fate."
Very little peer-review research comes out of private companies. A lot of their fundamental research is contracted to outside institutions such as academic institutions or foundations. Companies are primarily interested in product development and impose rigid quality control.

\section{Assessment}

Medical laboratory scientists and students often debate what is required to succeed in research. In the past years, the debate has centered on the achievement of advanced degrees, but publication has also been recognized as a hallmark of success. Essentially, the level of education in an academic institution is judged in comparison to other university departments. In order to be able to direct and perform independent research and obtain funding a graduate level degree is necessary. The MLS who wants to prepare for a profession in research academics should read the articles in the Clinical Laboratory Science journal that discuss the subject of obtaining advanced degrees including the newlydeveloped professional Doctorate in Clinical Laboratory Science (DCLS). ${ }^{9-13}$

Students and clinicians interested in research should participate in educational programs that emphasize research. They should also take courses in grant-writing and manuscript preparation. Many research institutions provide guides for clinical investigators that outline policies, procedures and other protocols.

Publishing requires involvement. Get involved with your professional societies. Present a case report at a scientific session. Medical laboratory scientists can present abstracts or posters at professional society meetings or write articles for local, regional or national journals. If you need help with a topic or format, discuss it with peers, professors or medical directors. They are usually delighted to exchange meaningful ideas which enhance the profession. Study the publications in print to get an idea of substance and format.

Don't get discouraged. If you have ideas that are important to you and research that can with-stand the peer-review process, someone will publish your work. Once that work is accepted, it will stand on its own merits. 


\section{CLINICAL PRACTICE}

\section{SUMMARY}

There are many positive aspects in the research setting as well as a few negative ones. This article should have provided you with information you need to make an educated career choice regarding the research laboratory as a workplace. The research setting has different employment characteristics than the traditional hospital laboratory. These should be evaluated thoughtfully to determine suitability to the individual interested. Issues of position stability, hours of work, salary, expectations, advancement opportunities, and others need to be considered.

Two extensive literature searches were performed by the author and a highly skilled medical library staff. Some of the references in this article may seem dated but very few texts or articles have covered this subject in any kind of detail

\section{REFRENCES}

1. Bates, DV. The role of scientific research and of research workers. Ann of NY Acad Sci. 1988;534:904.

2. Littlefield, JW. The need to promote careers that combine research and clinical care. J Med Educ. 1986;61:785.

3. American Society of Clinical Laboratory Science. www.ascls.org. Career Opportunities-Research and Product Development. Access date 03.26.10.

4. United States Department of Labor. Bureau of Labor Statistics. Occupational Outlook handbook, 2010-11 ed. Clinical Laboratory Technologists and Technicians.
5. Koehler A. Top 10 reasons to be a medical laboratory scientist. Advance. 2010;22:14.

6. www.Investopedia.com. Access date 08.17.10.

7. University of Texas Health Science Center, San Antonio, TX at www.uthscsa.edu. Accessed 08.17.10.

8. Testimonial. www.ascls.org. Access date 03.26.10.

9. Harmening-Pittiglio D. Professional development for faculty and students: New opportunities and directions. Clin Lab Sci. 1989;2:93.

10. Kotlarz VA. Tracing our roots: new opportunities and new challenges in clinical laboratory science (1977-1992). Clin Lab Sci. 2001;14:13-8.

11. McCoy C. Future directions for the clinical laboratory scientist. Clin Lab Sci. 2003;16:66.

12. Fowler D, Martin T, Spence L. The clinical laboratory practitioner. Clin Lab Sci. 2005;18:199-202.

13. Ranne A. The roles of the clinical laboratory scientist. Clin Lab Sci. 2009;22:196-202.

\section{ACKNOWLEDGEMENT:}

Thanks to George Fritsma, MS, MLS, manager of The Fritsma Factor, Your Interactive Hemostasis Resource, www.fritsmafactor.com, for manuscript assistance.

Thanks to Suzanne Campbell, Ph.D., MLS(ASCP) ${ }^{\mathrm{CM}}$ Program Coordinator Seward County Community College/Area Technical School 520 N. Washington Liberal KS 67901 for "outstanding and demanding" editorial assistance in preparation of this manuscript.

The peer-reviewed Clinical Practice Section seeks to publish case studies, reports, and articles that are immediately useful, are of a practical nature, or contain information that could lead to improvement in the quality of the clinical laboratory's contribution to patient care, including brief reviews of books, computer programs, audiovisual materials, or other materials of interest to readers. Direct all inquiries to Perry Scanlan, PhD, MT(ASCP), Medical Technology, Austin Peay State University, Room D212, Sundquist Science Complex, Box 4668, Clarksville TN 37044.

Clinical Laboratory Science encourages readers to respond with thoughts, questions, or comments regarding these articles. Email responses to westminsterpublishers@comcast.net. In the subject line, please type the journal issue and lead author such as "CLIN LAB SCI 24(3) RE MCGLASSON". Selected responses may appear in the Dialogue and Discussion section in a future issue. Responses may be edited for length and clarity. We look forward to hearing from you. 